\title{
A review of 105 negligence claims against accident and emergency departments
}

\author{
Armond Gwynne, Paul Barber, Fiona Tavener
}

\begin{abstract}
Objective-To examine 105 successive negligence claims against NHS accident and emergency (A\&E) departments in the United Kingdom and to highlight risk management points.

Methods-A systematic review of sociodemographic, clinical, and legal issues was conducted on each claim.

Results-54 claims involved the missed diagnosis of a fracture because of failure to $x$ ray or to interpret the films correctly; 27 claims alleged a missed or delayed diagnosis other than fracture and were mainly due to incomplete clinical examination or failure to $x$ ray or to interpret the films correctly; 24 claims alleged clinical mismanagement in the A\&E department; in 82 claims $(78 \%)$ an SHO was allegedly responsible for the mistake. By the end of August 1996, 92 claims (87.6\%) had been closed, of which 38 had been settled out of Court and 54 had not been pursued by the patient after disclosure of the records and-where appropriate-a repudiation of liability. Of the 13 claims remaining open, seven are considered to be defensible and six will have to be settled.
\end{abstract}

Conclusions-SHOs employed in A\&E departments need careful training and supervision, with ready access to senior medical advice, both clinical and radiological. Most errors leading to claims appear in retrospect to have been simple failures of history taking, physical examination, interpretation of radiographs, and communication. Poor quality notes imply substandard care. About half the claims were found to be indefensible. $(\mathcal{A}$ Accid Emerg Med 1997;14:243-245)

Keywords: medical negligence; accident and emergency departments; litigation

Negligence claims against NHS hospitals continue to increase, are unpleasant for everyone involved, and are costly. Liability for the negligent acts and omissions of NHS hospital medical and dental staff was transferred from the medical defence organisations to the employing authorities on 1 January 1990 . No comprehensive national collection of data about claims has been carried out, either before or since that time. This regrettable situation should be about to improve, with the establishment in 1996 of the Litigation Authority and the Clinical Negligence Scheme for Trusts. ${ }^{1}$ The data presented in this paper are derived from Bevan
Ashford's case files on instructions received from 23 hospitals of varying size and geographical distribution. Only claims primarily involving the accident and emergency (A\&E) department were included; some claims initiated against $\mathrm{A} \& \mathrm{E}$ staff actually involved another specialty, such as orthopaedics.

A search of published reports revealed little similar research of this nature. Hawkins and Paterson ${ }^{2}$ reviewed 100 claims which included a few from A\&E departments in the West Midlands, but gave little detail. Capstick and Edwards reported on 100 obstetric claims. ${ }^{3}$ Guly ${ }^{4}$ considered missed diagnoses in the A\&E department but not their legal outcome. Neale ${ }^{5}$ analysed 100 medicolegal cases to find the reasons for legal claims against doctors, but these were in the fields of gastroenterology and general medicine. Body ${ }^{6}$ looked at civil and criminal actions against anaesthetists. Hulbert et al audited 32 claims against four $A \& E$ departments and concluded that litigation is uncommon, litigation costs reasonable, and that early reporting of $x$ rays probably reduces the risk of litigation. Richmond and Evans ${ }^{8}$ looked at 72 complaints raised against one $\mathrm{A} \& \mathrm{E}$ department between 1983 and 1985, 13 of which became claims leading to four settlements. We therefore hope that this review may be useful to practitioners in $\mathrm{A} \& \mathrm{E}$.

Table 11370 Consecutive NHS hospital negligence claims referred by Bevan Ashford, Solicitors, to $\operatorname{Dr} A L$ Grynne between 1.4 .90 and 30.11 .96 broken down by specialty

\begin{tabular}{lrr}
\hline Obstetrics (175) and gynaecology (187) & 362 & $26.4 \%$ \\
Surgery & 249 & $18.2 \%$ \\
Orthopaedics & 209 & $15.3 \%$ \\
Medicine & 122 & $8.9 \%$ \\
A\&E & 133 & $9.7 \%$ \\
Paediatrics & 51 & $3.7 \%$ \\
Anaesthetics & 48 & $3.5 \%$ \\
Neurosurgery & 47 & $3.4 \%$ \\
Opthalmology & 37 & $2.7 \%$ \\
ENT & 28 & $2.1 \%$ \\
Dental & 26 & $1.9 \%$ \\
Psychiatry & 23 & $1.7 \%$ \\
Radiology & 18 & $1.3 \%$ \\
Others & 17 & $1.2 \%$ \\
Total & 1370 & $100 \%$ \\
\hline
\end{tabular}

Table 2 Issues considered in each claim

Nature of allegation

Sex, age and occupation of patient

Place of accident and type of referral (eg, direct, by ambulance, by GP)

Whether a complaint preceeded the formal claim for damages Why the true diagnosis was missed at the first opportunity and which member of staff was primarily responsible

$X$ ray reporting issues, where relevant

State of the claim, whether open or closed, defensible or indefensible

Risk management points arising 
Table 3 Catagories of claim

\begin{tabular}{lr}
\hline Missed or delayed diagnosis of a fracture & 54 \\
2 Missed or delayed diagnosis other than fracture & 27 \\
3 Alleged clinical mismanagement in the A\&E & \\
$\begin{array}{l}\text { department } \\
\text { Total }\end{array}$ & 24 \\
\hline
\end{tabular}

Table 4 Fractures missed

Femur (including 8 neck of femur or subcapital)
Tibia and/or fibula
Ankle
Hand
Radius and ulna
Wrist (other than scaphoid)
Scaphoid
Foot
Spine
Others [mandible (1), shoulder (2), elbow (1),
larynx (1), pelvis (1), skull (1)]

Tibia and/or fibula

Foot

Others [mandible (1), shoulder
larynx (1), pelvis (1), skull (1)

24

Risk management aims to identify, assess, and reduce risks to patients and, while important in all hospital departments, is indispensable in high risk ones. As shown in table 1 , no fewer then 1075 negligence claims out of 1370 arose from just five specialties. Significantly, the order of the top five has remained unchanged over the six years of data collection. $A \& E$ has always been perceived, in medicolegal circles at least, ${ }^{9}$ as being a high risk specialty and this is confirmed in these data.

\section{Methods}

A systematic review was conducted into each case. The issues considered are shown in table 2 .

Table 5 Missed or delayed diagnoses other than fracture

\begin{tabular}{ll}
\hline $\begin{array}{l}\text { Dislocations (clavicle (1), shoulder (posterior) (1), } \\
\text { metacarpals (2)) }\end{array}$ & 4 \\
Damage to tendons and ligaments & 8 \\
Ruptured Achilles' tendon (4) & \\
Patellar (1) & \\
Anterior cruciate (1) & 3 \\
Flexor tendons, hand (2) & \\
Nerve damage & \\
Radial (1) & 4 \\
Median (1) & \\
Ulnar (1) & \\
Vascular damage & \\
Deep vein thrombosis (1) \\
Leaking aortic aneurysm (1) \\
Extradural haematoma (no fracture - 1) \\
Compartment syndrome (leg) (1) \\
Retained foreign bodies \\
Knee (1) \\
Thumb (1) \\
Hand (1) \\
Foot (1) \\
Medical care \\
Failure to diagnose and admit cases of: \\
Pneumothorax, bronchopneumonia, myocardial \\
infarction and acute pancreatitis
\end{tabular}

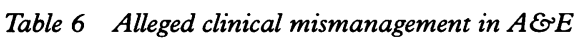

Mismanagement of fractures

Failure to refer for internal fixation (2)

Unsatisfactory plaster or delay in application (2)

Inadequate reduction of fracture (3)

Mismanagement of dislocations

All relating to fingers and failure of reduction and fixation

Surgical mismanagement

Failure to remove tourniquet from great toe following nail removal

Nursing mismanagement

Failure to administer injection correctly-tissue damage, burn from plaster saw

Miscellaneous, including

Mismanagement of septic fingers (3)

Failure to refer to appropriate medical or surgical specialists (6)

Alleged use of wrong drug or method of wound closure (2)
Results

Three broad categories of claim were identified and are shown in table 3. A summary of fractures missed is shown in table 4. Missed or delayed diagnoses other than fractures are classified in table 5 . The clinical mismanagement allegations are summarised in table 6 . Table 7 shows the age and sex distribution of the patients who became claimants. Between ages 15 and 45 years the majority $(77.4 \%)$ of claimants were men, but after 45 years there was a marked preponderance $(80.6 \%)$ of women. The women were most often injured or fell ill at home or in a public place, whereas the men tended to sustain injury or fall ill at work, during sport, or in a motor accident (particularly when riding a motorcycle). Most $(67.6 \%)$ went direct to hospital, while $21 \%$ were taken there by ambulance and $11.4 \%$ were referred by a general practitioner. The main occupational groupings, taken from the $A \& E$ records, are shown in table 8.

Sometimes a formal complaint precedes a claim for damages and this aspect was examined. Twenty two patients first used the hospital's complaints procedure, 11 men and 11 women. Considering that the most common age group for the male claimants was 20 to 30 years, it is perhaps noteworthy that only one man in his 20 s lodged a complaint and he was a health authority employee. Working people rarely complained - only four out of the 45 in the sample. Half of all hospital complaints were made within the first week, and half of all complaints were answered by an explanation and an apology. About one third of the complainants were told that the standard of care had been appropriate and that therefore negligence was denied. Nearly three quarters of those patients who received an apology then proceeded to claim damages, but only about half of them were successful, the remainder choosing not to pursue a claim after seeing the records.

The main reasons for each of the three categories of claim are shown in table 9, which also indicates which grade of $\mathrm{A} \& \mathrm{E}$ doctor was responsible. In some cases there was more than one important act or omission leading to the claim.

The SHO grade dominates the results in all three categories of claim, followed by GP/

Table 7 Age and sex of claimants

\begin{tabular}{lrl}
\hline Children up to 15 & 12 & $(5 \mathrm{~m}, 7 \mathrm{f})$ \\
$15-30$ years & 34 & $(30 \mathrm{~m}, 4 \mathrm{f})$ \\
$30-45$ years & 28 & $(18 \mathrm{~m}, 10 \mathrm{f})$ \\
$45-60$ years & 14 & $(3 \mathrm{~m}, 11 \mathrm{f})$ \\
$60-75$ years & 10 & $(2 \mathrm{~m}, 8 \mathrm{f})$ \\
$75+$ & 7 & $(1 \mathrm{~m}, 6 \mathrm{f})$ \\
Total & 105 & $(59 \mathrm{~m}, 46 \mathrm{f})$ \\
\hline
\end{tabular}

Table 8 Main occupational groupings of claimants

\begin{tabular}{lr} 
Manual workers & 16 \\
Children & 14 \\
Retired & 14 \\
Professional & 11 \\
Unemployed & 11 \\
Catering & 5 \\
Students & 5 \\
Other & 29 \\
Total & 105 \\
\hline
\end{tabular}


Table 9 Reasons for wrong diagnosis and grade of $A \mathcal{E} E$ doctor responsible

\begin{tabular}{lr}
\hline Category $1-$ missed/delayed diagnosis of fracture & \\
Failure to $x$ ray (17 SHOs, 5 GP/clinical assistants, 1 staff grade specialist) & 23 \\
Failure to interpret $x$ ray correctly (15 SHOs, 3 GP/clinical assistants, 1 staff grade, & 26 \\
$\quad 7$ radiologists) & \\
Category $2-$ missed/delayed diagnosis, non-fracture & 11 \\
Failure to examine thoroughly (9 SHOs, 2 GP/clinical assistants) & 5 \\
Failure to $x$ ray or to specify appropriate view (4 SHOs, 1 staff grade) & 7 \\
Failure to interpret $x$ ray correctly (4 SHOs, 1 GP/clinical assistant, 2 radiologists) & 7 \\
\hline
\end{tabular}

clinical assistants and then by a few staff grade specialists. This is unsurprising since in most A\&E departments relatively inexperienced SHOs are the front line doctors. A\&E registrars, senior registrars, and consultants featured rarely in this assessment of liability. In the missed fracture group, the predominant reason for the mishap-and therefore the claim-was either a failure to $x$ ray at all or a failure to interpret the films correctly. In category 2 , failure of thorough physical examination of the patient occurred in 11 cases; in five cases there was a failure to order an $x$ ray where one was indicated (or to specify the appropriate view), and in seven cases the principal error was failure to interpret the films correctly. Remarkably, this last error was perpetuated on two occasions by a radiologist. In category 3 the main areas of fault are summarised in table 6 .

Prompt reporting of A\&E films by a radiologist proved to be of the greatest importance in minimising avoidable damage to patients and therefore in reducing claims and costs. In 11 cases drawn from the first two categories the radiologist reported the film correctly on review, which led to the patient being recalled and appropriate treatment instituted. In other cases the correct diagnosis was eventually made at another hospital, at the fracture clinic of the same hospital, by the general practitioner referring them for further $x$ ray, or even at medicolegal examination much later, for example for an insurance claim.

By the end of August 1996, 92 claims $(87.6 \%)$ were closed, of which 38 had been settled out of Court, while 54 had not been pursued by the patient after record disclosure and where appropriate a formal repudiation of liability. Of the 13 claims remaining open, seven are considered to be defensible and some of these are likely to go to trial. The remaining six will probably have to be settled.

\section{Discussion}

SHOs employed in A\&E departments must be properly trained and supervised, and ideally should always have immediate access to senior help and advice, both clinical and radiological. As a counsel of perfection in risk management, most claims would not have arisen if SHOs' decisions had been approved by a senior member of staff before the patient left the department. All A\&E films should be reported upon as quickly as possible by a radiologist. Wardrope and Chennells asked, in $1985,{ }^{10}$ "Should all casualty radiographs be reviewed" and today we answer "emphatically yes".
All the classic pitfalls of A\&E practice are featured in this series, and while everything is easy with hindsight, the claims arose mainly through simple errors such as failure to take a carefully detailed history of the accident, incomplete physical examination, and failure to $x$ ray. The legal test is whether a missed or delayed diagnosis led directly to damage to the patient; if not, he is not entitled to damages even if there was a breach of the duty of care. Certainly $x$ rays are costly and may be harmful, but these two points do not amount to a defence to a charge of negligence if, on the facts of the particular case, it is clear that an $x$ ray would have revealed the diagnosis and influenced treatment. The importance of good clinical records featured strongly in this series; high quality records suggest high quality care and even when the diagnosis was missed, can help to refute an allegation of negligence. The reverse is equally true-poor records imply poor care, a point often stressed by the patient's $A \& E$ expert.

The other hardy perennial risk management point is the importance of good communications between doctor and patient, between all members of the $A \& E$ staff and between the department and the family doctor.

The last claim in this series arose from a clinical incident in 1994 and since then many more A\&E claims have been notified. At risk of sounding complacent, however, perhaps the surprising thing - given the present nature of $A \& E$ practice and staffing arrangements-is that there are not many more negligence claims. This must surely be a reflection of the quality of care achieved, often under hectic and stressful circumstances, by inexperienced juniors and their trainers and supervisors. This review seems to suggest that with just a little more care the number of claims in this area could be reduced further and-facing ever increasing damages and legal costs from this area of practice-Trust managers might be able to improve standards of care and reduce costs by employing fewer SHOs and more senior doctors.

We thank Dr H R Guly, consultant in A\&E at Derriford Hospital, Plymouth, for his great help in planning this project.

1 The National Health Service Litigation Authority (Establishment and Constitution) Order 1995 (SI 1995 No 2800) and The National Health Service (Clinical Negligence Scheme) Regulations 1996 (SI 1996 No 251).

2 Hawkins C, Paterson I. Medicolegal audit in the West Midlands region: analysis of 100 cases. BMJ 1993;307:1483-7. Capstick JB, Edwards PJ. Trends in obstetric malpractice claims. Lancet 1990;336:931-2.

4 Guly HR. Missed diagnoses in an A\&E department. Injury 1984;15:403-6.

5 Neale G. Clinical analysis of 100 medicolegal cases. BMJ 1993;307:1483-7.

6 Body DI. Civil and criminal actions against anaesthetists. $\mathrm{Br}$ J Anaesth 1994;73:83-92.

7 Hulbert DC, Riddle WL, Longstaff PM, Belstead JS, Beckett MW. An audit of litigation costs in four accident and emergency departments. J Accid Emerg Med 1996;13. 400-1.

8 Richmond PW, Evans RC. Complaints and litigation-three years experience at a busy accident and emergency departyears experience at a busy accident and emergenc

9 Hawkins C. Mishap or malpractice? Oxford: Blackwell, 1985: $130-42$

10 Wardrope J, Chennells PM. Should all casualty radiographs be reviewed? BMJ 1985;290:1638-40. 